\title{
The role of cultural intelligence of managers in promoting employees' collaboration
}

\author{
Seyed Ali Akbar Ahmadi ${ }^{\mathrm{a}}$, Hosein Safarzadeh ${ }^{\mathrm{b}}$, Mohammad Javad Hozoori $^{\mathrm{a}}$, Fariba Dehnavi ${ }^{\mathrm{c}^{*}}$
}

${ }^{a}$ Public management Department, Payame Noor University, 19395-4697 ,Tehran, I.R. of IRAN

${ }^{b}$ Management Department, Islamic Azad University, Central Tehran Branch, Tehran, I.R. of IRAN

${ }^{c}$ PhD Candidate of Public Administration in Payame Noor University, Tehran, I.R. of IRAN

\section{CHRONICLE ABSTRACT}

\begin{tabular}{l}
\hline Article history: \\
Received March 12, 2013 \\
Received in revised format \\
10 June 2013 \\
Accepted 22 June 2013 \\
Available online \\
June 252013 \\
\hline Keywords: \\
Cultural Intelligence \\
Collaboration \\
Cooperation \\
Social Security Organization
\end{tabular}

\section{Introduction}

In the book titled "The Evolution of Cooperation" by Robert Axelrod (1984, p190) we read: "We are used to thinking about competitions in which there is only one winner. But the world is rarely like that. In a vast range of situations mutual cooperation can be better for both sides than mutual defection. The key to doing well lies not in overcoming others, but in eliciting their cooperation" (Thomson et al., 2008) and collaboration goes beyond cooperation or coordination (Thomson \& Perry,

\begin{abstract}
Collaboration can be a very challenging process precisely because it is a highly intense way of working, requiring new ways of thinking, behavior and ways of operating. Cultural Intelligence (CI) is an antecedent for collaboration . The primary goal of this survey is to investigate the relationship between cultural intelligence of managers and their employees' collaboration. This research is a descriptive-correlation study where 119 managers and 175 employees are selected by stratified random sampling from the Social Security organization managers and their workers. To measure cultural intelligence, the Iranian version of the cultural intelligence questionnaire is implemented and collaboration is measured using a questionnaire developed by the researcher. The Cronbach's alpha reliability coefficient respectively for cultural intelligence and collaboration questionnaires are 0.933 and 0.813 , respectively, which are well above the minimum acceptable limit. Data collected using SPSS 19 and they are analyzed using LISREL 8.54 software packages. The results indicate a significant and positive relationship between cultural intelligence among managers and their employees' collaboration. As the relationship between motivational and behavioral CI dimensions and collaboration is also determined to be positive and significant. Based on demographic factors such as gender, age and education we cannot comment on the cultural intelligence of managers and employee's collaboration but having inter-cultural experiences has had a positive impact on the cultural intelligence of managers. Based on the findings obtained we can say that Cultural Intelligence is a key factor, influencing and determining for collaboration.
\end{abstract}

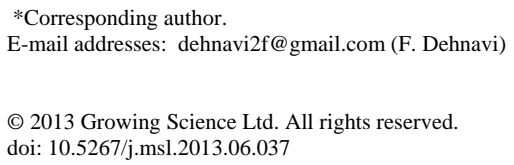


2006) and strong relationship and high commitment between two or more people are normally needed (McDonald \& Rosier, 2011). In the today's world, there are many issues such as globalization phenomenon, technological growth as well as economic and political, which have reformed nature of work and organizations have changed and different forms of collaboration have further prevailed and expanded, accordingly (Gibson \& Dibble, 2008). Therefore, managers who can perceive complicated and changeable nature of collaboration are more geared up for collaboration as compared with those who just concentrate on individual objectives (Grisham, 2006). In addition, cross-cultural contexts are ranging from a local identity to an international/global one wherein diversity is further growing (Grisham, 2006). Under such conditions, individuals with various cultures may have various perceptions of their similar problems and difficulties based on their knowledge and cultural ideologies leading to misperceptions and conflict, which could appear as obstacles for collaboration (Chua et al., 2011) and to have a better perception and embarking on better cross-cultural cooperation we need to consider cultural differences.

Some people believe that a simple approach to overcome cultural differences and promote crosscultural effectiveness is to learn more about the differences among cultures. In another words, effective performance of today's organizations is in need of cultural intelligence (Afkaneh, 2010). Some other studies indicate that individuals with higher cultural intelligence can better adjust themselves to the current complex and unpredictable situations (Livermore, 2011) and their capacities for having on productive collaboration will help them be responsive to the changes in the environment (Gibson \& Dibble, 2008). Henceforth all managers need to become familiar with cultural intelligence to reach an effective organizational modeling for dealing with various challenges and generating better performance in their job (Sadeghian, 2011). Therefore, we need for further attention of the human resource managers for collaboration process (Asadnejad Rokni \& Safari, 2009) and for this purpose cultural intelligence, as a whole new way of seeing the world and as a strong possibility will further promote our effectiveness in diverse cultural contexts (Livermore, 2011).

The relationship between two concepts as cultural intelligence and collaboration needs to be investigated more comprehensively especially in Iranian community. Therefore, the purpose of the present research is to address the main question facing us in this respect: Whether cultural intelligence can ensure collaboration or not? It is to be mentioned that within the Iranian multi-cultural society organizations and institutions are home to staff and personnel with different exquisite tribal and domestic cultural backgrounds (Kurd, Lor, Turk, Arab, Baluch, etc.). In addition, Iranian Social Security Organization, as one the biggest organizations in Iran, is no exception to this fact. Therefore, in this paper, we intend to investigate the role of cultural intelligence of the Social Security Organization managers in collaboration between their personnel.

\section{Literature review}

\subsection{Concept of collaboration}

Bollen et al. (1989), Carmines and Zeller (1983) and Long (1983a, 1983b) considered social science variables as obstruct concepts, which cannot be witnessed in the real world and errors repeatedly happen in their assessment. Collaboration is one of these concepts/constructs; the concept/contract that cannot defined and worked with given the fact that no consensus among the researchers as to its real meaning exists (Thomson, et al., 2007). The interesting point is that the cooperation between one organization and other organizations happens normally and not necessarily willingly; the cooperation that may not happen under normal circumstances (Kenny, 2012). The theoretical discussion on the collaboration construct was originally introduced by different researchers and different elements were mentioned on this concept (Garry, 1989, 1996, 2000; Huxham, 1996, 2005; Ring \& Vendenvin, 1994; Helrigel et al., 1986; Thomson et al., 2007). Grey (1989, 1995) considered collaboration as a process wherein every individual views different perspective of a certain problem attempting to reach at a 
solution beyond his limited vision (Thomson \& Perry, 2006). Table 1 displays the differences between the concepts as follows:

\section{Table 1}

Comparison between distinctions of coordination, cooperation \& collaboration (Kenney, 2012)

\begin{tabular}{|c|c|c|c|}
\hline Distinctions & Cooperation & Coordination & Collaboration \\
\hline Definition & $\begin{array}{l}\text { Can bring profit or loss to } \\
\text { either party; The work } \\
\text { environment is competitive; } \\
\text { Relations between members } \\
\text { is limited to their work and } \\
\text { responsibilities. } \\
\text { Static goals }\end{array}$ & $\begin{array}{l}\text { By Organizing the different } \\
\text { individual efforts for the sake of a } \\
\text { common purpose; } \\
\text { Members do not need to have } \\
\text { relationships with others beyond their } \\
\text { work. } \\
\text { Static goals }\end{array}$ & $\begin{array}{l}\text { In creating a product members have } \\
\text { to reach agreement and it ensures } \\
\text { profit for all; Competition is } \\
\text { considered as an obstacle; } \\
\text { Relationship between individuals go } \\
\text { beyond their work and } \\
\text { responsibilities. } \\
\text { Dynamic goals }\end{array}$ \\
\hline $\begin{array}{l}\text { Precondition for } \\
\text { success }\end{array}$ & $\begin{array}{l}\text { Common goals; presence of } \\
\text { more than one individual; } \\
\text { mutual respect and trust; } \\
\text { mutual understanding; and } \\
\text { joint effort }\end{array}$ & $\begin{array}{l}\text { Common goals; presence of more than } \\
\text { one individual; it must be cleared who } \\
\text { shall do what and when. }\end{array}$ & $\begin{array}{l}\text { Common goals, dynamic processes; } \\
\text { sense of belonging; open } \\
\text { relationships; mutual trust and } \\
\text { respect; supplementary skill; smart } \\
\text { agility }\end{array}$ \\
\hline Enabling factors & $\begin{array}{l}\text { Proper tools; consultation and } \\
\text { exchange of knowledge; } \\
\text { transparency in } \\
\text { responsibilities }\end{array}$ & $\begin{array}{l}\text { Proper tools; problem solving } \\
\text { mechanisms }\end{array}$ & $\begin{array}{l}\text { Proper configuration of individuals; } \\
\text { skills for promoting cooperation and } \\
\text { operational cooperation }\end{array}$ \\
\hline $\begin{array}{l}\text { Freedom in doing } \\
\text { work }\end{array}$ & Noticeable & At minimum level & Important and vital \\
\hline Physical presence & Notic & At minimum level & Important and vital \\
\hline $\begin{array}{l}\text { The reason behind } \\
\text { using }\end{array}$ & $\begin{array}{l}\text { Mutual benefits with } \\
\text { partnership in work }\end{array}$ & $\begin{array}{l}\text { Avoidance of split and overlapping in } \\
\text { work }\end{array}$ & $\begin{array}{l}\text { Reach desirable outcome resulted } \\
\text { from collective cooperation; the result } \\
\text { that cannot be achieved from solitary } \\
\text { work }\end{array}$ \\
\hline Desirable outcome & $\begin{array}{l}\text { Efficient outcome, saving } \\
\text { time and costs }\end{array}$ & Efficient outcome & $\begin{array}{l}\text { Efficient outcome; saving time and } \\
\text { costs; innovation; excellent work; and } \\
\text { collective work }\end{array}$ \\
\hline Desirable use & $\begin{array}{l}\text { Settling problems in complex } \\
\text { environments and systems }\end{array}$ & $\begin{array}{l}\text { Coordination among responsibilities, } \\
\text { roles and programs in simple } \\
\text { environments }\end{array}$ & $\begin{array}{l}\text { Reach shared vision within complex } \\
\text { environments and systems }\end{array}$ \\
\hline Example & $\begin{array}{l}\text { Marriage; public utility plan; } \\
\text { helping flood affected peoples }\end{array}$ & $\begin{array}{l}\text { Use of information technology; } \\
\text { settling traffic problems }\end{array}$ & $\begin{array}{l}\text { Brain storming; improvisation in } \\
\text { theatre and music }\end{array}$ \\
\hline Proper tools & $\begin{array}{l}\text { Systemic thinking; analytical } \\
\text { tools (root analysis) }\end{array}$ & $\begin{array}{l}\text { Project management; time schedule; } \\
\text { critical path method; Gantt Chart; } \\
\text { operational list (who, where,...) }\end{array}$ & $\begin{array}{l}\text { Inquiry and research; open-ended } \\
\text { meetings; four fold operation ; } \\
\text { dialogue; story telling }\end{array}$ \\
\hline
\end{tabular}

Some researchers have stated that cooperation and collaboration are different in terms of interactions, integration, commitment and complexity. Cooperation stands at the lowest part of the continuum and collaboration stands at the highest known with collective performance (Thomson \& Perry, 2006). The continuum has been displayed in Fig. 1 as follows:

\section{Increasing}

Interdependence risks and rewards commitments and contribution increasing collaboration

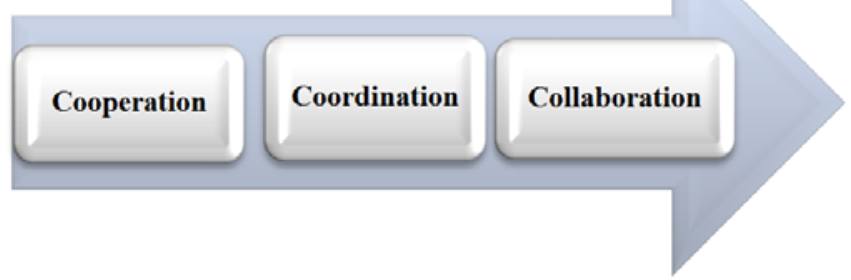

Fig.1. The collaboration continuum, based upon ARACY, 2009.

McDonald \& Rosier, 2011

The quality of a collaborative relationship often depends on some factors including trust, mutual respect, shared vision, frequent communication and flexibility. Identification of values and 
characteristics of members of the group is the pre-requirement to a successful cooperation. In addition, by employing the conflict between individual and collective desires and maximizing of synergy between individual differences many organizations are able to make dynamic changes in their activities (Thomson et al., 2008) and specific abilities to adjust to such conditions and circumstances is called as the cultural intelligence.

\subsection{Cultural intelligence}

The Cultural intelligence concept, as a kind of intelligence, includes a set of individual capacities, which stands against personal desires and characteristics and it is different from other types of intelligence like general cognition and emotional intelligence. Some researchers like Earley and Ang (2003), Plum et al. (2008) have introduced this concept as a three-dimensional concept and others like Ang et al. (2007), Van Dyne et al. (2009), Livermore (2011), Ng et al. (2012), have considered it as a four-dimensional one. Earley and Ang (2003), employed the Sternberg multiple-intelligence, conceptualized the cultural intelligence based on meta-cognitive, cognitive, motivational and behavioral dimensions to be practiced in the environments with cultural diversity. Meta-cognitive intelligence is associated with the control of cognition, the processes individuals implement to acquire and understand knowledge and cognitive intelligence is associated with to a person's knowledge structures. Motivational intelligence is associated with the mental capacity to direct and sustain energy on a particular task or situation and recognize that motivational capabilities are critical to 'real world' problem solving. Dimensions of the cultural intelligence construct have been displayed in Fig. 2 as follows:

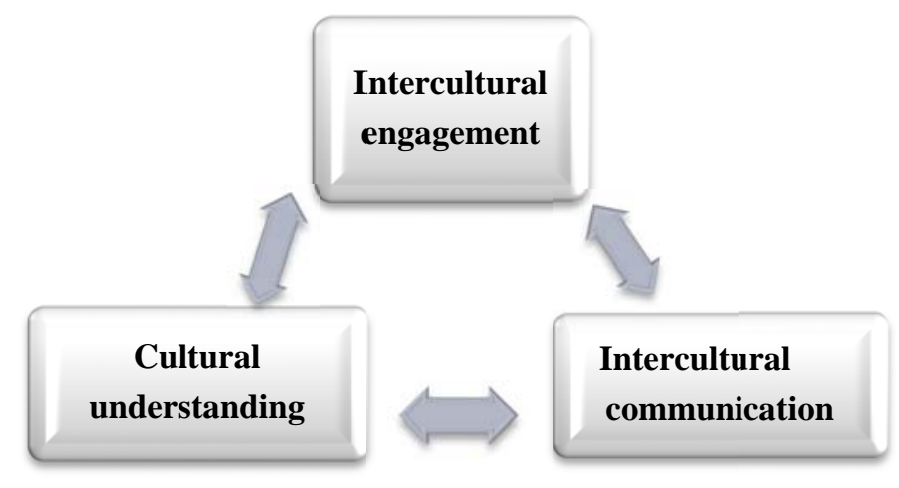

Fig. 2. The three dimensions of Cultural Intelligence

Plum, 2007, 2008

This model defines organizations as complex adaptive systems, which depends on a constant flow of information in all directions. It is not a hierarchical model where the top of the pyramid has the knowledge and the information to make decisions on behalf of others. In this framework, the firm is expected to learn to adapt and equality is assumed even though there are power differences between people depending on their role.

\subsubsection{Cultural intelligence studies}

There are large numbers of studies on assessment and measurement of cultural intelligence, which could be divided into three categories. The first one discusses the interdependence among variables like performance and intelligence and its components. The second one concentrates on the factors positively influencing intelligence and the last one concentrates on the performance and consequences of intelligence like job performance (Shaffer \& Miller, 2008). Literature map of the cultural intelligence has been displayed in Fig. 3. In this figure, direct and indirect relationships of 
this concept/construct with several concepts/constructs in Iran and other countries have been taken into account. The collaboration also is visible among such variables. While very limited number of researches has been accomplished on the relationship between cultural intelligence with collaboration in Iran. For the same purpose, the present research intended to investigate the cultural intelligence as well as effect of this important factor on collaboration.

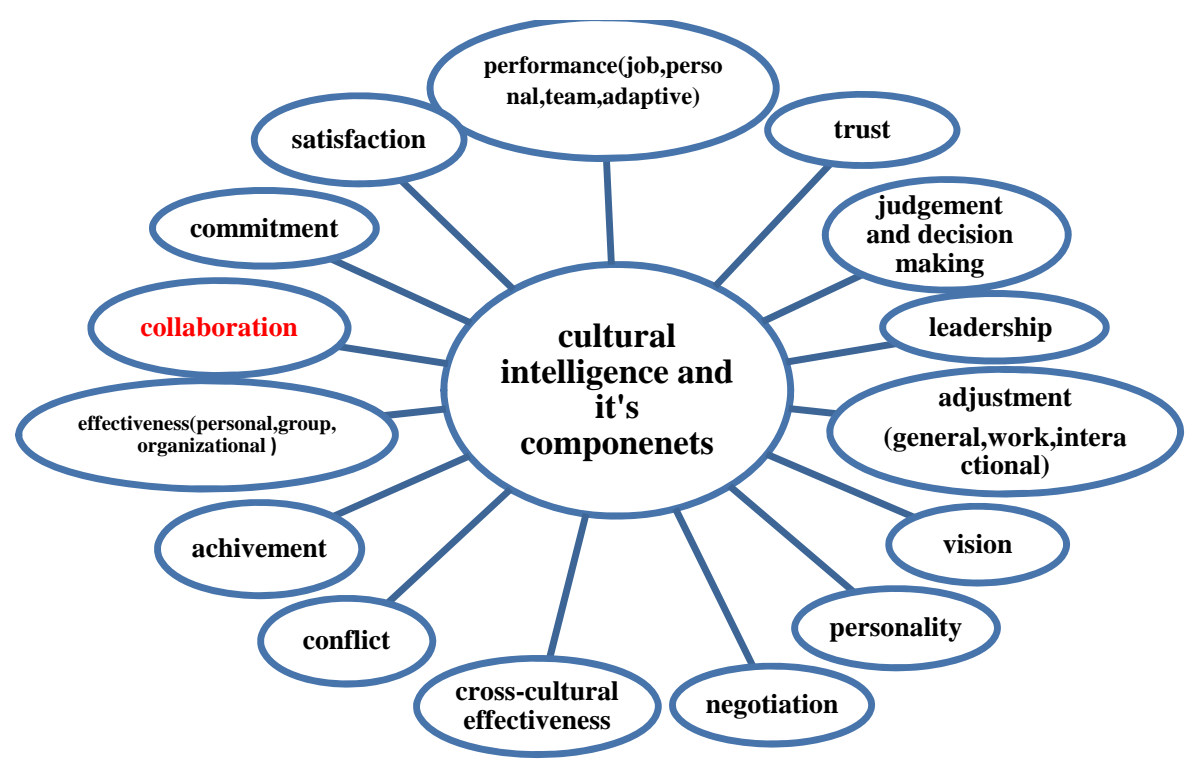

Fig. 3. Research map of the cultural intelligence

\subsection{Collaboration and cultural intelligence}

We need to accept that old way of thinking cannot produce any solution to the today challenges and cultural difficulties encountering the complex firms and we have to develope our way of thinking and produce new modelings (Plum, 2008). We, all, have been witnessing successful types of multicultural collaboration in various environments including consulting services, medical care and emergency, film making, relife efforts by peace activists, scientific researches, etc. As the result of these multicultural collaboration objective results are produced (Gibson \& Dibble, 2008,). In Fig. 4, four categoties of such an adjuastment (from low effort and minor modification to high effort and substantial collaborative evolution) within a continum are demonstrated.

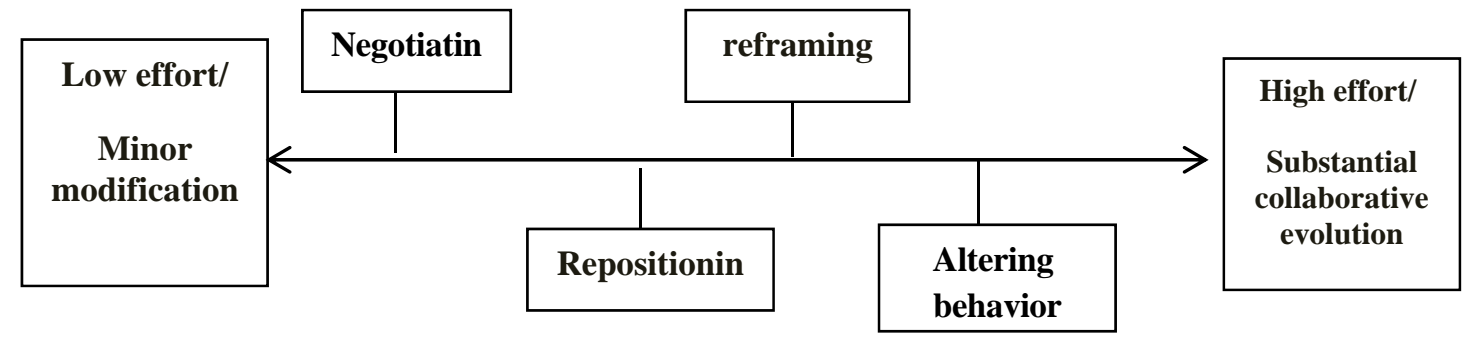

Fig. 4. Forms of Collaboration External Adjustment (Gibson \& Dibble, 2008)

The most problematic form of adjustment is associated with the change in behavior of members of the cooperation team within a strange environment. This type of adjustment has to deal with the changes happen in the work processes, change of the work method, development of new roles, change in time schedule, time rescheduling of production and delivery process.

According to Janssens and Brett (2006) factors influencing creative realism in global teams are demonstrated in Fig. 5 as follows, 


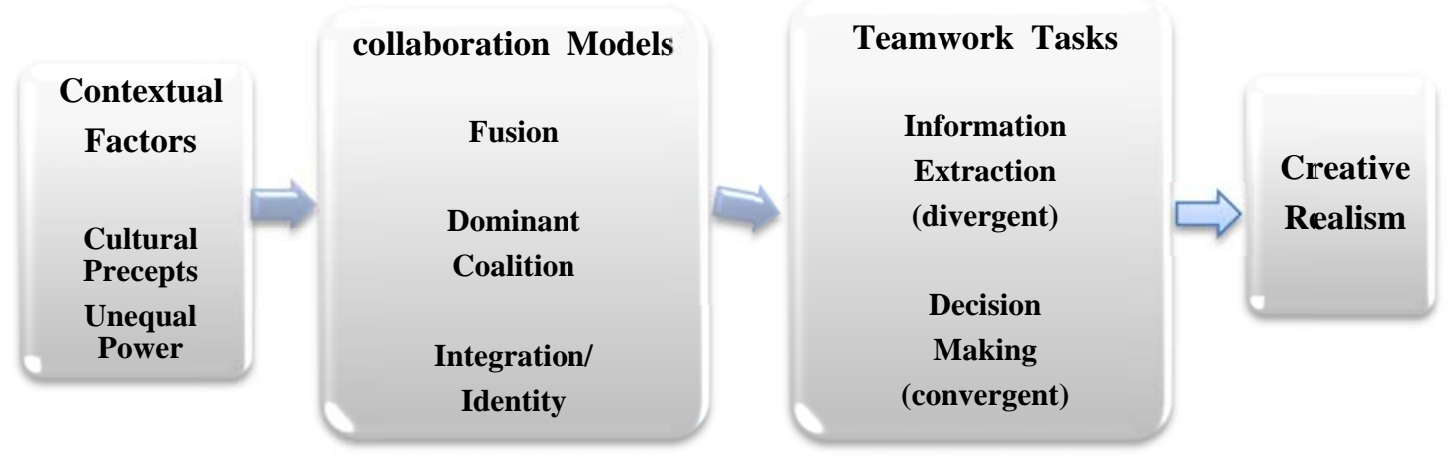

Fig. 5. Factors Influencing Creative Realism in Global Teams

Janssens\& Brett ,2006, p131

As we can observe from Fig. 5, this framework provides guidelines to reduce process losses and produce creatively realistic decisions. This model of collaboration "fuses" or combines various cultural precepts for teamwork while maintaining the distinct flavor of various precepts and then implements this fused process of collaboration to address the tasks of information extraction and decision making (Green et al.,2005; Janssens \& Brett, 2006). Chua et al. (2011), in three separate studies, investigated the effect of the meta-cognitive cultural intelligence on the growth of collaboration with mediation of affect-based trust as demonstrated in the following table:

Table 2

Results of three separate studies of Chua et al., 2011

\begin{tabular}{|c|c|c|c|}
\hline & First research & Second research & Third research \\
\hline Variables & $\begin{array}{l}\text { Independent: meta-cognitive } \\
\text { intelligence and international } \\
\text { experience of manager } \\
\text { Dependent: affect-based trust } \\
\text { and creative collaboration of } \\
\text { managers }\end{array}$ & $\begin{array}{l}\text { Independent: meta- } \\
\text { cognitive cultural } \\
\text { intelligence } \\
\text { Dependent: affect- } \\
\text { based trust and new } \\
\text { ideas sharing }\end{array}$ & $\begin{array}{l}\text { Independent: meta-cognitive cultural } \\
\text { intelligence } \\
\text { Dependent: creative collaboration } \\
\text { Mediator: affect-based trust }\end{array}$ \\
\hline $\begin{array}{l}\text { Community } \\
\text { /sample }\end{array}$ & $\begin{array}{l}43 \text { middle managers and those } \\
\text { who were connected with the } \\
\text { manager (observer with } \\
\text { different cultures) }\end{array}$ & $\begin{array}{l}60 \text { managers of high } \\
\text { technological } \\
\text { institutions in the } \\
\text { private sector }\end{array}$ & $\begin{array}{l}\text { Out of } 118 \text { two- member student groups } \\
\text { (with different cultures and without any } \\
\text { prior knowledge), } 63 \text { groups randomly came } \\
\text { under affect-based trust conditions ( } 10 \\
\text { minutes warm up) and the rest came under } \\
\text { full control. }\end{array}$ \\
\hline
\end{tabular}

Outcome: Managers with higher meta-cognitive intelligence are more affect based on the collaboration context (first research); managers with less meta-cognitive intelligence are weaker in dealing with new ideas in the cross-cultural context (second research); and managers with higher meta-cognitive intelligence are stronger in sharing new ideas and more creative in their performance(third research) (Nielsen, 2004; Chua et al., 2011).

Primary hypothesis: There is significant relationship between cultural intelligence and collaboration.

\section{Methodology}

\subsection{Research conceptual model}

In view of the researches already spoken of and definition produced by Plum (2010) implying that cultural intelligence (with cognitive, motivational and practical dimensions) is necessary for collaboration. Fig. 6 shows the proposed study of this paper. 


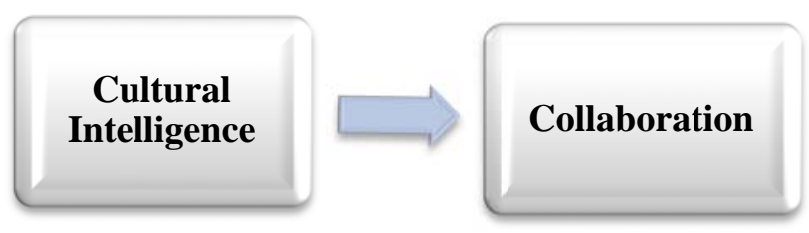

Fig. 6. Conceptual Model, relationship between cultural intelligence and collaboration

\subsection{The hypotheses of the survey}

Based on the above-mentioned model hypotheses of the research were produced as follows:

Primary hypothesis: There is significant relationship between cultural intelligence of managers and employee's collaboration of the Social Security Organization.

First secondary hypothesis: There is significant relationship between cognitive cultural intelligence of managers and employee’s collaboration of the Social Security Organization.

Second secondary hypothesis: There is significant relationship between motivational cultural intelligence of managers and employee’s collaboration of the Social Security Organization.

Third secondary hypothesis: There is significant relationship between behavioral cultural intelligence of managers and employee's collaboration of the Social Security Organization.

\subsection{Materials and methodology}

In the matter of its nature, the present research is applied one and in the matter of methodology, it is considered as a survey research. For analysis of the information, the descriptive and inferential statistics as well as correlation analysis have been utilized.

\subsubsection{Community and sampling}

The statistical community of the present research included managers and personnel of the general departments of the Social Security Organization from different parts of the country. Based on the sample size (sample volume) formula (Kukran) out of the 542 members of the statistical community (194 managers and 348 personnel) the sample volume was calculated in two categories of managers (132) and personnel (186) and samples of the research were selected based on stratified random sampling and the questionnaires, answered and submitted by 119 managers and 175 personnel, were analyzed accordingly.

\subsubsection{Research tool}

The research tool for the present research included questionnaire. For measuring cultural intelligence of managers the (Iranian) cultural intelligence questionnaire, which consists of 16 questions in three dimensions of cognitive, motivational and behavioral cultural intelligence and the collaboration was measured and assessed by the researcher-made questionnaire(comprising 11 questions) that eleventh question is revers question.

\subsubsection{Validity and reliability of the questionnaires}

For having a reliable assessment a pretest was organized with participating of managers and dependent personnel. For both questionnaires the Cronbach alpha coefficient (Cronbach>0.7) was calculated implying high reliability of the questionnaires as displayed in Table 3. 
Table 3

Reliability tests of the questionnaires, with Cronbach alpha coefficient

\begin{tabular}{cccc}
\hline $\begin{array}{c}\text { Cognitive cultural } \\
\text { intelligence }\end{array}$ & $\begin{array}{c}\text { Motivational cultural } \\
\text { intelligence }\end{array}$ & $\begin{array}{c}\text { Behavioral cultural } \\
\text { intelligence }\end{array}$ & Collaboration \\
\hline 6 Questions & 5 QUESTIONS & 5 QUESTIONS & 11 Questions \\
0.941 & 0.918 & 0.849 & 0.813 \\
\hline
\end{tabular}

With the purpose of assessing validity of the cultural intelligence questionnaire, semantic validity of the words were confirmed by language and literature experts and in the collaboration questionnaire validity of the collaboration concept/construct was measured by use of LISREL software 8.54 and the measurement model (as displayed in Table 4).

\section{Table 4}

Content validity of the collaboration questionnaire

\begin{tabular}{llccc}
\hline $\mathrm{N}$ & \multicolumn{1}{c}{ Question } & T statistic & Significance \\
\hline 1 & $\begin{array}{l}\text { I extend active cooperation in identifying requirements and working priorities. } \\
2\end{array}$ & $\begin{array}{l}\text { There exists mush eagerness in me and my colleagues for finding new way of } \\
\text { thinking, new behavior and new work method. }\end{array}$ & 3.26 & 0.01 \\
3 & To become professional I discuss my ideas and thoughts with my colleagues. & 6.41 & 0.01 \\
4 & To solve problems I will let others ask questions and present their solutions. & 5.21 & 0.01 \\
5 & I respect other individuals' ideas (and coexist with them). & 6.14 & 0.01 \\
6 & When I am needed I will spare no effort. & 4.72 & 0.01 \\
7 & In making decisions and selecting solutions I will give priority to dialogue. & 10.27 & 0.01 \\
8 & When I want to make decision and solve problems I take views of others into my & 11.99 & 0.01 \\
& serious attention. & 9.80 & 0.01 \\
9 & I attach more value to collective work rather than individual one. & 10.73 & 0.01 \\
10 & I have a good understanding of my responsibilities. & 10.01 & 0.01 \\
11 & I think my job is more important than others(Rev). & & \\
\hline
\end{tabular}

Results indicated that the t-value calculated for each marker with latent variable of collaboration stood above 1.96 implying validity of questions of the questionnaire for measuring the concept at this stage.

\section{Results}

Demographic Characteristics of samples were extracted as displayed in Table No.5 as follows:

\section{Table 5}

The frequency distribution of demographic variables

\begin{tabular}{|c|c|c|c|}
\hline & Age variable & Gender & Education \\
\hline Managers & $63 \% \quad 40-50$ years old & $82 \% \quad$ Male & $46.2 \% \quad \mathrm{BA}$ \\
\hline Employees & $43 \% \quad 30-40$ years old & 64\% Female & $64 \% \quad$ BA \\
\hline
\end{tabular}

In order to investigate normality of variables distribution the Skewness test also known as Koran test was employed. Table 6 has displayed the results as follows:

\section{Table 6}

Normality tests of research variables distribution based on Koran test

\begin{tabular}{ccccc}
\hline Latent variables of the model & Cognitive & Motivational & Behavioral & Collaboration \\
\hline Chi-square value & 1.034 & 1.320 & 1.246 & 1.615 \\
Significance & 0.104 & 0.075 & 0.085 & 0.058 \\
\hline
\end{tabular}

According to Table 6 and given the significance level above 0.05 for all variables, normal distribution for all variables was confirmed. For calculating the effect of demographic variables on the research variables, mean tests were utilized and the results are displayed on Table 7 as follows: 
Table 7

Results of the comparison of the average at demographic variable levels

\begin{tabular}{llllll}
\hline Variables & Group & compare mean test & Statistic & Sig. & Result \\
\hline \multirow{2}{*}{ Age } & Managers cultural Intelligence & ANOVA & 0.326 & 0.723 & Not sig \\
\multirow{2}{*}{ Education } & Employee's Collaboration & ANOVA & 0.089 & 0.915 & Not sig \\
& Managers cultural Intelligence & ANOVA & 2.414 & 0.094 & Not sig \\
\multirow{2}{*}{ Gender } & Employee's Collaboration & ANOVA & 0.813 & 0.445 & Not sig \\
\multirow{2}{*}{ cross-cultural experience } & Managers cultural Intelligence & Independent T.T & 1.847 & 0.067 & Not sig \\
\hline ** Significance at error level of 5\% with confidence level of 95\% & Managers cultural Intelligence & Independent T.T & 2.669 & 0.009 & sig \\
\hline
\end{tabular}

The results indicated: On the variables of age and gender and education for both managers and the employees the significance level of statistic was above 0.050 therefore sufficient reason was not found to reject the null hypothesis. But the effect of cross-cultural experience for managers was meaningful $(p=0.009)$. For testing hypotheses and investigating intensity of relationship between variables of cultural intelligence and collaboration the Pearson Correlation Coefficient was employed the results of which has been displayed in Table No.8 as follows:

\section{Table 8}

Correlation between cultural intelligence of managers and employee's collaboration (Number of managers $=119$, number of employees $=175$ )

\begin{tabular}{ccccc} 
Latent variables & Total intelligence & Cognitive intelligence & $\begin{array}{c}\text { Motivational } \\
\text { intelligence }\end{array}$ & $\begin{array}{c}\text { Behavioral } \\
\text { intelligence }\end{array}$ \\
\hline $\begin{array}{c}\text { Employee's } \\
\text { Collaboration }\end{array}$ & 0.181 & 0.172 & 0.200 & 0.198 \\
$\begin{array}{c}\text { Significance } \\
\text { Relationship }\end{array}$ & $\begin{array}{c}0.049 \\
\text { Confirmed }\end{array}$ & $\begin{array}{c}0.061 \\
\text { Non-confirmed }\end{array}$ & $\begin{array}{c}0.029 \\
\text { Confirmed }\end{array}$ & $\begin{array}{c}0.031 \\
\text { Confirmed }\end{array}$ \\
\hline
\end{tabular}

** Significance at error level of 5\% with confidence level of 95\%

Table No.8 indicated that: Given significance level of below 5\% in the relationship between total cultural intelligence, motivational cultural intelligence and behavioral cultural intelligence one side and collaboration on the other side there existed sufficient reason to reject the null hypothesis implying significance of such relationships. In other words, positive significant relationship between the total cultural intelligence and two motivational and behavioral dimensions of managers on one side and employee's collaboration on the other side was confirmed. In addition, the significance level value of the relationship between the cognitive cultural intelligence and the collaboration was found to above $\mathrm{p}>0.05$. On the basis it was cleared that there exited no significant relationship between cognitive cultural intelligence and collaboration in this study.

\section{Discussion}

Collaboration is facing diverse challenges and opportunities including economic ones(inflation, assessment or stability of currency), political ones(government change, public unrest, military coup), technological ones(failure of a certain technology, modern technologies), the human resource related ones (access to specialized staff with low income) and finally cultural ones (different cultural values, prejudgments, cultural development,...) (Gibson \& Dibble, 2008). It also can be admitted that one of the secrets behind the success of managers in containing organizational challenges is to give priority to cultural intelligence and its dimensions (Anbarestani, 2011). Vedadi et al. (2010) termed cultural intelligence as one of the most important indicators of the success of Iranian oil and gas industry' managers. In 1999 AllahVerdi specified that there existed positive significant relationship between motivational cultural intelligence and strategy cultural intelligence on one side and performance of bank governors of public and private banks in the city of Isfahan. 
In the present research, based on the hypotheses test (as displayed in Table 8) the significant positive relationship between total cultural intelligence $(p=0.049)$ and its motivational $(p=0.029)$ and behavioral $(\mathrm{p}=0.031)$ dimensions on one side and collaboration on the other side was confirmed and the research model as demonstrated in Fig. 8 was finalized.

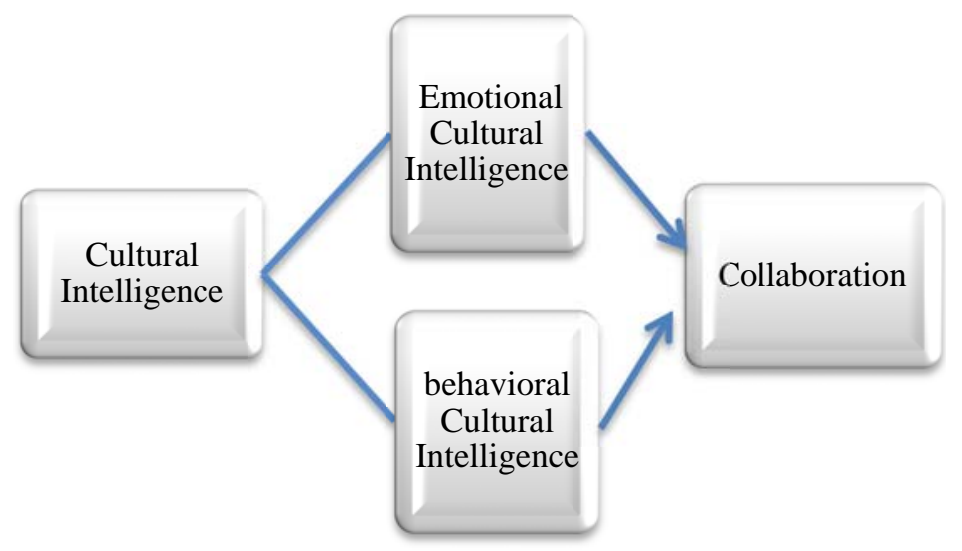

Fig. 8. Research model, relationship between cultural intelligence and collaboration

Findings of the present research confirmed results of the previous researches. For example, the research carried out by Imai and Golfand (2010) specified that in the cross-cultural dialogue, total and motivational cultural intelligence can predict consistent behavior and behavioral cultural intelligence will give rise to cooperation-based strategies (Chua et al., 2011). Based on the findings of the present research existence of a significant relationship between cognitive cultural intelligence and collaboration $(\mathrm{p}=0.061)$ was not confirmed that is on contrary to the findings of Kerani and Breth (2009). They claimed that individuals with high meta-cognitive cultural intelligence would achieve effective and creative cross-cultural collaboration through involvement in the multicultural combined working teams (Chua et al., 2011).

Also, results of the compare mean tests indicated that variables of education, age and gender did not influence on the cultural intelligence of managers and employee's collaboration ( $>0.05$ ) implying that we cannot make judgment on the cultural intelligence of managers based on the said variables. These results actually were consistent with findings of the Livermore research implying that relationship between individuals' cultural intelligence and their adjustment and compatibility is much stronger than the relationship between their cultural intelligence and their age, gender, experience, place of residence or even their intelligence quotient (Livermore, 2011). In 2011 Sadeghian stipulated that demographic characteristics (like age, gender, education and managerial posts) do not affect their cultural intelligence that is to say cultural intelligence does not increase with higher education level although the need to further educate managers is undeniable (Sadeghian, 2011). This occurs while it seems that there is significant difference between managers with cross-cultural experience (working, living or studying irrespective of their place of residence) and those without cross-cultural experience $(p=0.009)$ in the matter of the cultural intelligence and cultural intelligence of managers with crosscultural experience is much higher than other managers. These findings confirmed outcome of the research carried out by Crown in 2008 stipulating that education and employment in different cultures of cognitive and motivational dimensions would give rise to cultural intelligience and it is the best way for promoting of cultural intelligence and further involvement in cross-cultural interactions. Finally, the more duration and number of experience mangers have within the work place. The more cultural intelligence for them will be produced (Deng \& Gibson, 2008).

\section{Conclusion}

The present research as the first field study inspired by theoretical definition by Plum (2010) investigated the relationship between cultural intelligence and collaboration by use of the cultural 
intelligence three dimensional model. Although based on its outcome the relationship between motivational and behavioral cultural intelligence on one side and collaboration was found to be significant $(\mathrm{p}<0.05)$ implying that having managers with motivational and behavioral cultural intelligence will give rise to further collaboration of the employee but this relationship between the cognitive cultural intelligence dimension and the collaboration was not confirmed $(\mathrm{p}>0.05)$. Therefore, it is suggested that in the future studies the restrictions of present research to be eliminated and the researches include possible recommendations in the relevant programs. Also the relationship between the cognitive dimension and even meta-cognitive cultural intelligence (fourth dimension) on one side and the collaboration on the other side is needed to be further investigated, because there is an assumption that knowledge of the cultural pre-assumptions of ours and others (meta-cognitive intelligence) would lead to promotion of collaboration (Chua et al., 2011; Zad et al., 2013). It is hoped that results of this effort will shed further light in the way of other beloved researchers opening a new window of opportunity for future studies and researchers in this respect.

\section{References}

Afkaneh, M. (2011). The relationship between cultural intelligence and the individual performance of employees: Ministry of Welfare and Social Security. Master Thesis, Shahed University.

Allahverdi, Z. (2008). Cultural intelligence of chiefs of state and private banks of Isfahan and its impact on their performance based on the balance card (BSC) pattern , the Social Sciences, No. 7, Summer.

Anbarestani, H. (2011). The relationship between cultural intelligence and emotional intelligence of managers and organizational performance. Sistan and Baluchestan University, Master's thesis in the field of management.

Ang, S., Van Dyne, L., Koh, C., Ng, K. Y., Templer, K. J., Tay, C., \& Chandrasekar, N. A. (2007). Cultural intelligence: Its measurement and effects on cultural judgment and decision making, cultural adaptation and task performance. Management and Organization Review, 3(3), 335-371.

Ang, S., Van Dyne, L., \& Tan ,M.L.(2011). The Cambridge Handbook of Intelligence. Cultural intelligence , Chapter 29, Edited by Robert J. Sternberg and Scott Barry Kaufman, Cambridge University Press, www.cambridge.org.

AsadNejad Rokni, M. \& Safari Kahreh, M. (2009). Virtual Collaboration in working teams, human resource management research magazine, challenges and strategies. Department of Social and Cultural Studies / research group for management, training and human, 44, 137-165.

Asghari Zadeh, E., \& Ghasemi, A. R. (2010). Cultural intelligence and its function in organizations. Journal of Cultural Engineering, 41-42, 80-70.

Bahari, L. (2008). Relationship between cultural intelligence and transformational leadership in the social security in Fars province. Payam Noor University, Master's thesis.

Bucher, R. D., \& Bucher, P. L. (2008). Building cultural intelligence (CQ): Nine megaskills. Pearson/Prentice Hall.

Chua, R.Y.J., Morris, M.W., \& Mor, S. (2011). Collaborating across cultures: Cultural metacognition \& affect-based trust in creative collaboration. Harvard University, Harvard Business School: 1-63.

Deng, L., \& Gibson, P. (2008). A qualitative evaluation on the role of cultural intelligence in crosscultural leadership effectiveness. International journal of leadership studies, 3(2), 181-197.

Earley, P. C., \& ANG, S. A. (2003). Cultural intelligence: Individual interactions across cultures. Stanford business books.

Gibson, C. B., \& Dibble, R. (2008). Culture inside and out: Developing a collaboration's capacity to externally adjust. Handbook of cultural intelligence: Theory, measurement, and applications, 221240.

Green, A. L., Hill, A. Y., Friday, E., \& Friday, S. S. (2005). The use of multiple intelligences to enhance team productivity. Management Decision, 43(3), 349-359. 
Grisham, T. (2006). Metaphor, poetry, storytelling and cross-cultural leadership.Management Decision, 44(4), 486-503.

Ha, B. C., Park, Y. K., \& Cho, S. (2011). Suppliers' affective trust and trust in competency in buyers: Its effect on collaboration and logistics efficiency. International Journal of Operations \& Production Management, 31(1), 56-77.

Janssens, M., \& Brett, J. M. (2006). Cultural Intelligence in Global Teams A Fusion Model of Collaboration. Group \& Organization Management, 31(1), 124-153.

Kenney, J. (2012). Collaboration in Minnesota: Supporting Families \& Youth in the Jordan Neighborhood. http://en.wikipedia.org/wiki/Collaborative, 5/1/2013.

Khodadady, E., \& Ghahari, S. (2011). Validation of the Persian cultural intelligence scale and exploring its relationship with gender, education, travelling abroad and place of living. Global Journal of Human Social Science, 11(7), 63-75.

Livermore, D.A. (2011). The cultural intelligence difference: master the one skill you can't do without in today's global economy, (1-19), www.amacombooks.org, 5/1/2013.

McDonald, M., \& Rosier, K. (2011). Interagency collaboration, Australian Family Relationships Clearinghouse AFRC Briefing, 21-A, 1-10.

Nielsen, B. B. (2004). The role of trust in collaborative relationships: A multi-dimensional approach. Management, 7(3), 239-256.

Ng, K. Y., Van Dyne, L., Ang, S., Ryan, F. T. L., \& Oswald, F. L. (2011). Cultural intelligence: A review, reflections, and recommendations for future research. Conducting multinational research projects in organizational psychology. Washington, DC: American Psychological Association.

Plum, E., Achen, B., Dræby, I., \& Jensen, I. (2008). CI: Cultural Intelligence: the Art of Leading Cultural Complexity. Middlesex University Press.

Roy, M. H., \& Dugal, S. S. (1998). Developing trust: the importance of cognitive flexibility and cooperative contexts. Management Decision, 36(9), 561-567.

Sadeghian, E. (2011). Presenting of the effectual cultural intelligence model of manager on effectiveness Iran Khodro organization of Iran. European Journal of Scientific Research, 61(3), 401-414.

Shaffer, M., \& Miller, G. (2008). Cultural Intelligence: A key success factor for expatriates. In S. Ang \& L. Van Dyne (Eds.), Handbook of Cultural Intelligence: Theory, Measurement and Applications,(pp.107-124).Armonk, NY.

Slater, J.J. (2006). Creating collaborations: From isolationism to community. International Journal of Educational management, 20(3), 215-223.

Tariq, A., Aslam, H. D., Habib, M. B., Siddique, A., \& Khan, M. (2012). Enhancing Employees’ Collaboration Through Trust in Organizations:(An Emerging Challenge in Human Resource Management). Mediterranean Journal of Social Sciences, 3(1). 599-565.

Thomas, D. (2008). Cultural Intelligence: People Skills for Global Business: Easyread Super Large 20pt Edition. ReadHowYouWant. com.

Thomson, A. M., \& Perry, J. L. (2006). Collaboration processes: Inside the black box. Public administration review, 66(s1), 20-32.

Thomson, A. M., Perry, J. L., \& Miller, T. K. (2009). Conceptualizing and measuring collaboration. Journal of Public Administration Research and Theory, 19(1), 23-56.

Thomson, A. M., Perry, J. L., \& Miller, T. K. (2008). Linking collaboration processes and outcomes. Collaborative Public Management, 97-120.

Vedadi, A., Kheiri, B., \& Abbasalizadeh, M. (2011). The relationship between cultural intelligence and achievement: a case study in an Iranian company. Iranian Journal Management Studies, 3, 2538.

Zad, H. P., Poornazarpoor, S., Dovein, H. F., \& Hamedan, I. (2013). Relationship between cultural intelligence of coaches and effectiveness of the Iranian men's national team members. Life Science Journal, 10(5s), 405-410. 